\title{
Novel Fmoc-Polyamino Acids for Solid- Phase Synthesis of Defined Polyamidoamines
}

2011

Vol. 13, No. 7

1586-1589

\section{David Schaffert, Naresh Badgujar, and Ernst Wagner*}

Pharmaceutical Biotechnology, Department of Pharmacy, Center for Drug Research, and Center of NanoScience, Ludwig-Maximilians-Universität Munich, Butenandtstr. 5-13, D-81377 Munich, Germany

ernst.wagner@cup.uni-muenchen.de

Received December 1, 2010

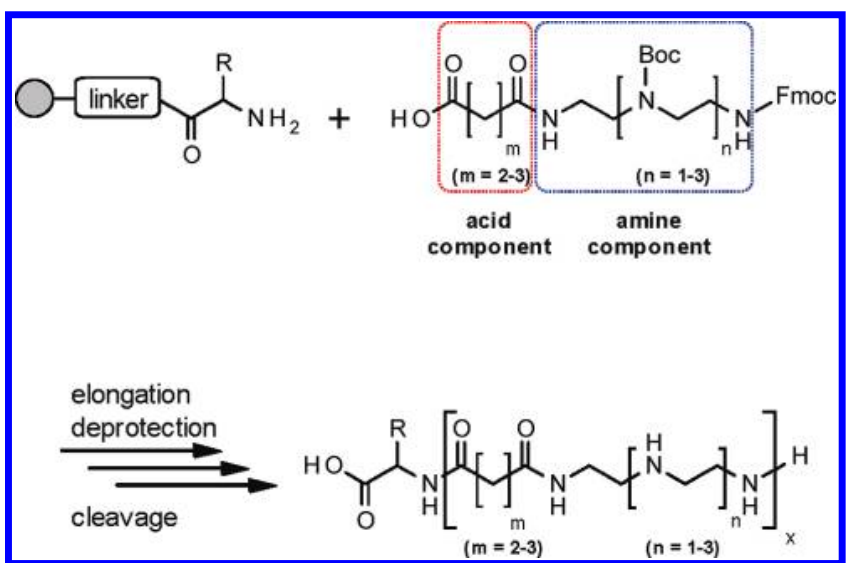

A versatile solid-phase approach to sequence-defined polyamidoamines was developed. Four different Fmoc-polyamino acid building blocks were synthesized by selective protection of symmetrical oligoethylenimine precursors followed by introduction of a carboxylic acid handle using cyclic anhydrides and subsequent Fmoc-protection. The novel Fmoc-polyamino acids were used to construct polyamidoamines demonstrating complete compatibility to standard Fmoc reaction conditions. The straightforward synthesis of the building blocks and the high efficiency of the solid-phase coupling reactions allow the versatile synthesis of defined polycations.

Polyamines are involved in a number of biological functions such as neuromodulation, ${ }^{1}$ cell proliferation, ${ }^{2}$ and DNA condensation, ${ }^{3}$ constituting important templates in drug design ${ }^{4}$ and synthetic scaffolds in alkaloid

(1) Fiori, L. M.; Gustavo, T J. Psvchiatrv Neurosci. 2008, 33, 102 110.

(2) Seiler, N.; Raul, F. Cell. Mol. Med. 2005, 9, 623-642.

(3) Remy, J.-S.; Sirlin, C.; Vierling, P.; Behr, J.-P. Bioconiugate Chem. 1994, 5, 647-654.

(4) Melchiorre, C.; Bolognesi, M. L.; Minarini, A.; Rosini, M.; Tumiatti, V. J. Med. Chem. 2010, 53, 5906-5914.

(5) Hashimoto, T.; Yamada, Y. Annu. Rev. Plant Phvsiol. Plant Mol. Biol. 1994, 45, 257-285.

(6) Tomalia, D. A.; Baker, H.; Dewald, J.; Hall, M.; Kallos, G.; Martin, S.; Roeck, J.; Ryder, J.; Smith, P. Polvm. J. 1985, 17, 117.

(7) (a) Felgner, P. L.; Gadek, T. R.; Holm, M.; Roman, R.; Chan, H. W.; Wenz, M.; Northrop, J. P.; Ringold, G. M.; Danielsen, M. Proc. Natl. Acad. Sci. U.S.A. 1987, 84, 7413. (b) Wang, X. L.; Jensen, R.; Lu, Z. R. J. Controlled Release 2007, 120, 250. and heterocycle synthesis. ${ }^{5}$ Furthermore they are key components in the syntheses of gene delivery systems such as PAMAM dendrimers, ${ }^{6}$ cationic lipids, ${ }^{7}$ or linear poly(amidoamines). ${ }^{8}$ Poly(amidoamines) have received a lot of scientific attention because of their favorable properties regarding DNA compaction, ${ }^{9}$ solubility, and biocompatibility as well as their favorable properties regarding hemolysis and cytotoxicity ${ }^{10}$ compared to other commonly used polymers such as poly(L-lysine $)^{11}$ and

(8) Srinivasachari, S.; Liu, Y.; Zhang, G.; Prevette, L.; Reineke, T. M. J. Am. Chem. Soc. 2006, 128,8176 .

(9) Vuillaume, P. Y.; Brunelle, M.; Van Calsteren, M.-R.; LaurentLewandowski, S.; Bégin, A.; Lewandowski, R.; Talbot, B. G.; ElAzhary, Y. Biomacromolecules 2005, 6, 1769.

(10) Lavignac, N.; Lazenby, M.; Foka, P.; Malgesini, B.; Verpilio, I.; Ferruti, P.; Duncan, R. Macromol. Biosci. 2004, 4, 922-929.

(11) Wu, G. Y.; Wu, C. H. J. Biol. Chem. 1987, 262, 4429. 
Scheme 1. Building Block Synthesis

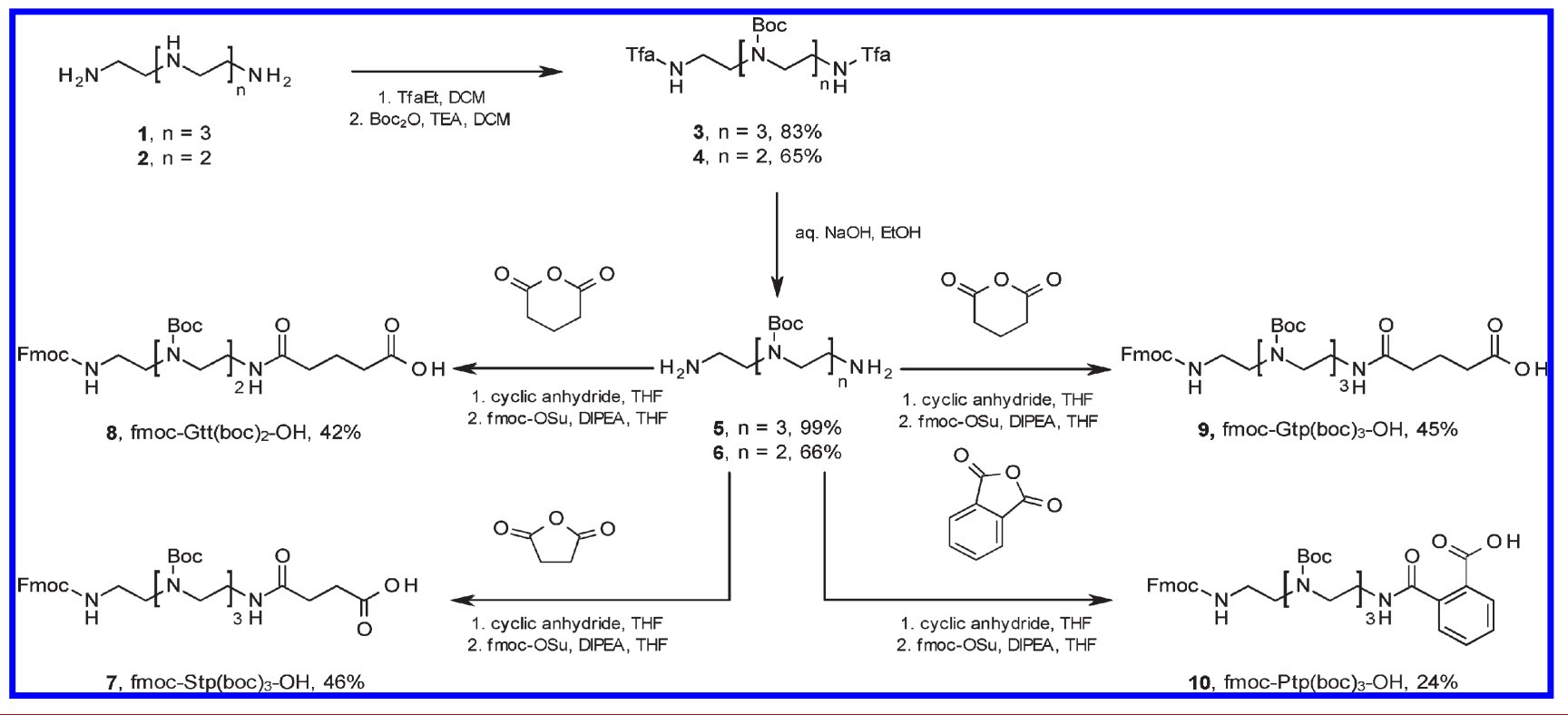

polyethylenimine. ${ }^{12}$ Poly(amidoamines) are classically synthesized by solution-phase polyaddition reactions ${ }^{13}$ resulting in a limited design space and products with a high degree of polydispersity.

A literature survey reveals that reports of the application of solid-phase chemistry to the synthesis of polyamidoamines are scarce and mostly deal with rather short target structures. ${ }^{14}$ The only examples for the synthesis of longer, linear polyamidoamines by a solid-phase methodology were reported by Hartmann et al. ${ }^{15}$ They employed a two-step condensation synthesis strategy characterized by an alternating assembly of the diacid succinic acid and diamines, which nicely demonstrated the feasibility of the approach. Our efforts to apply their strategy to larger oligoamines failed because of unexpected crosslinks which block further polymer extension (see Supporting Information). In this letter we report a versatile synthetic route to fmoc-polyamino acid building blocks and their use in solid-phase poly(amidoamine) synthesis. Use of these building blocks greatly improves the versatility and efficiency of solid-phase poly(amidoamine) synthesis.

In designing oligoethylenimine based building blocks compatible with Fmoc-SPPS protocols we introduced the

(12) Boussif, O.; Lezoualc'h, F.; Zanta, M. A.; Mergny, M. D.; Scherman, D.; Demeneix, B.; Behr, J. P. Proc. Natl. Acad. Sci. U.S.A. 1995, 92, 7297

(13) Ferruti, P.; Ranucci, E.; Di Silvestro, G.; Yuan, C.-M.; Caranzolo, N.; Donetti, R.; Marchisio, M. A. Chim. Ind. 1999, 81, 739-748.

(14) (a) Wells, N. J.; Basso, A.; Bradley, M. Peptide Science 1998, 47, 381. (b) Manku, S.; Laplante, C.; Kopac, D.; Chan, T.; Hall, D. G. $J$. Org. Chem. 2001, 66, 874. (c) Jørgensen, M. R.; Jaroszewski, J. W.; Witt, M.; Franzyk, H. Synthesis 2005, 2687.

(15) (a) Hartmann, L.; Krause, E.; Antonietti, M.; Borner, H. G. Biomacromolecules 2006, 7, 1239. (b) Hartmann, L.; Häfele, S.; PeschkaSüss, R.; Antonietti, M.; Börner, H. G. Macromolecules 2007, 40, 7771. (c) Hartmann, L.; Hafele, S.; Peschka-Suss, R.; Antonietti, M.; Borner, H. G. Chemistrv 2008, 14, 2025. carboxylic acid function at a terminal amino group by ringopening acylation with cyclic anhydrides (Scheme 1). To prevent side reactions during building block synthesis and SPPS, the secondary amines of the oligoethylenimines had to be protected. The primary and secondary amines of the polyamine scaffold were differentiated by selective acylation of the primary amines ${ }^{16}$ using ethyl trifluoroacetate. Secondary amines were protected as carbamates using ditert-butyl dicarbonate, allowing deprotection during global deprotection and cleavage from the resin. Alkaline hydrolysis of $\mathbf{3}$ and $\mathbf{4}$ yielded the corresponding Bocprotected diamines (5 and $\mathbf{6}$ ). The conversion of the symmetrical Boc-protected diamines into functionalized polyamino acids required a monoacylation in the first step, thereby differentiating the two amino functions. Desymmetrization reactions are by their nature low yielding and in the case of polyamines often involve laborious chromatographic purification procedures. We optimized a onepot strategy allowing introduction of the carboxylic acid function and subsequent fmoc protection of the remaining amino function. The yield limiting step was the desymmetrization reaction, so different reaction conditions were tested for an effective monoacylation. Acylation at $-70{ }^{\circ} \mathrm{C}$ using cyclic anhydrides followed by conversion into the

(16) (a) Xu, D.; Prasad, K.; Repic, O.; Blacklock, T. J. Tetrahedron Lett. 1995, 36, 7357. (b) Koscova; S.; Budesinsky; M.; Hodacova; J. G.; Czechoslovak Academy of Sciences, Institute of Organic Chemistry and Biochemistry: Praha, Tcheque Republique, 2003; Vol. 68, p 7.

(17) Bernatowicz, M. S.; Daniels, S. B.; Köster, H. Tetrahedron Lett. 1989, 30, 4645-4648.

(18) Chan, W. C.; White, P. D. Fmoc solid phase peptide synthesis: a practical approach; Oxford University Press: New York, 2000.

(19) Tam, J. P. Proc. Natl. Acad. Sci. USA. 1988, 85, 5409-5413.

(20) Li, Z.; Zhao, R.; Wu, X.; Sun, Y.; Yao, M.; Li, J.; Xu, Y.; Gu, J. Faseb J 2005, 19, 1978-1985.

(21) Schaffert, D., Dohmen, C.Wagner, E. Polymers for delivery of nucleic acids. European patent application 2010, EP10165502. 
Table 1. Synthesized PAAs

\begin{tabular}{|c|c|c|c|c|}
\hline no. & sequence & purity $^{a}$ & MALDI calcd & MALDI found \\
\hline \multirow[t]{2}{*}{11} & $\mathrm{H}_{2} \mathrm{~N}$-Stp-Stp-Stp-Stp-Stp-Trp-CONH ${ }_{2}$ & 98 & 1561.02 & $1561.9[\mathrm{MH}]$ \\
\hline & & & & $1583.2[\mathrm{MH}+\mathrm{Na}]$ \\
\hline \multirow[t]{2}{*}{12} & $\mathrm{H}_{2} \mathrm{~N}$-Gtt-Gtt-Gtt-Gtt-Gtt-Trp-CONH${ }_{2}$ & 97 & 1415.82 & $1416.4[\mathrm{MH}]$ \\
\hline & & & & $1438.4[\mathrm{MH}+\mathrm{Na}]$ \\
\hline \multirow[t]{2}{*}{13} & $\mathrm{H}_{2} \mathrm{~N}-\mathrm{Gtp}$-Gtp-Gtp-Gtp-Gtp-Trp-CONH${ }_{2}$ & 97 & 1631.15 & $1631.9[\mathrm{MH}]$ \\
\hline & & & & $1653.6[\mathrm{MH}+\mathrm{Na}]$ \\
\hline \multirow[t]{2}{*}{14} & $\mathrm{H}_{2} \mathrm{~N}-\mathrm{Ptp}$ - Ptp- Ptp- Ptp-Ptp-Trp-CONH${ }_{2}$ & 94 & 1801.24 & $1802.2[\mathrm{MH}]$ \\
\hline & & & & $1823.9[\mathrm{MH}+\mathrm{Na}]$ \\
\hline \multirow[t]{2}{*}{15} & $\left(\mathrm{H}_{2} \mathrm{~N}\right.$-Lys-Gtt-Stp-Gtp-Lys) ${ }_{2}$-Lys-Trp-CONH ${ }_{2}$ & 91 & 2443.21 & $2443.4[\mathrm{MH}]$ \\
\hline & & & & $2465.3[\mathrm{MH}+\mathrm{Na}]$ \\
\hline 16 & $\mathrm{H}_{2} \mathrm{~N}$-Stp-Stp-Tyr-His-Trp-Tyr-Gly-Tyr-Thr-Pro-Gln-Asn-Val-Ile-COOH & 97 & 2083.4 & $2084.9[\mathrm{MH}]$ \\
\hline
\end{tabular}

${ }^{a}$ IEX-HPLC purity at $220 \mathrm{~nm}$ of crude peptide. Elution by linear gradient from 0 to $100 \% \mathrm{~B}(\mathrm{~A}: 20 \mathrm{mM} \mathrm{NaCl}$ in $10 \mathrm{mM} \mathrm{HCl} \mathrm{pH} 2.2 ; \mathrm{B}: 3 \mathrm{M} \mathrm{NaCl}$ in $10 \mathrm{mM} \mathrm{HCl} \mathrm{pH} \mathrm{2.2).} \mathrm{Stp,} \mathrm{Gtt,} \mathrm{Gtp,} \mathrm{and} \mathrm{Ptp} \mathrm{are} \mathrm{the} \mathrm{deprotected} \mathrm{forms} \mathrm{of} \mathrm{compounds} \mathbf{7 , ~ 8 , ~ 9 , ~ a n d ~ 1 0 , ~ r e s p e c t i v e l y . ~}$

Fmoc-derivative by Fmoc-OSu proved to be the most effective route to fully protected polyamino acids $(\mathbf{7}, \mathbf{8}$, 9). This synthetic route allowed the isolation of the polyamino acids at very convenient yields above $40 \%$ of purified polyamines substituted with aliphatic anhydrides. Other strategies (complexation using 9-BBN, desymmetrization using Fmoc-OSu or Fmoc-Cl) did not further improve the yield of desymmetrization. Despite modest yields, these syntheses were performed on 10-30 g scales. Use of phthalic anhydride resulted in a lower product yield (10), most likely because of the acid lability of the product.

Polyamidoamines (PAAs) 11-15 (Table 1) were synthesized as carboxamides using Rink MBHA resin, ${ }^{17}$ preloaded with tryptophane as the first amino acid for an increased UV absorption of the products (Scheme 2). 16 was synthesized on a peptide synthesizer using a standard Wang linker, with manual introduction of the Stp units. A series of homopolymers (five repeating units) was synthesized to evaluate the coupling efficiency and overall performance of the different polyamino acid building blocks. The PyBOP/HOBt coupling and deprotection protocols used for the synthesis were described previously. ${ }^{18}$ Characterization of the PAAs was done by high performance cation-exchange chromatography, ${ }^{1} \mathrm{H}$ NMR, and MALDI-TOF MS.

The ${ }^{1} \mathrm{H}$ and ${ }^{13} \mathrm{C}$ NMR spectra of all building blocks and intermediates show different extents of line broadening of most of their signals and an increased measurement temperature $\left(50^{\circ} \mathrm{C}\right)$ leading to coalescence and sharpening of signals. ${ }^{16 \mathrm{~b}}$ Building blocks containing aliphatic diacids as a spacer $(\mathbf{7}, \mathbf{8}, \mathbf{9})$ displayed excellent coupling efficiencies and resulted in products $(\mathbf{1 1}, \mathbf{1 2}, \mathbf{1 3})$ with a crude purity of $>95 \%$ (exemplary HPLC traces are shown in Figure 1) after deprotection and cleavage from the resin. Building block 10, containing the phthalic acid spacer, demonstrated slightly positive Kaiser tests from time to time during the synthesis of its homosequence. This was observed independently from coupling time and used solvent. Despite this problem the purity of the crude product (14)

was above $90 \%$ demonstrating the feasibility of the synthetic protocols.

After successful homosequence synthesis the three building blocks containing aliphatic spacers $(\mathbf{7}, \mathbf{8}, \mathbf{9})$ were used to construct a mixed sequence with a branching point (15). The two-arm MAP-like ${ }^{19}$ structure was synthesized by incorporation of $N, N^{\prime}$-bis(fmoc)lysine as a second amino acid. The increased sterical demands enforced by the branching point and the combination of the different building blocks had no apparent influence on product quality.

To evaluate the use of the polyamino acid building block in a more complex protection group scheme as routinely applied in standard solid-phase peptide synthesis, we chose the moderately hydrophobic, EGFR targeting peptide GE $11^{20}$ and modified the sequence with two N-terminal Stp units. The peptide precursor was synthesized in a completely automatic fashion, checked for purity using RP-HPLC (see Supporting Information), and modified with two N-terminal Stp units. IEX-HPLC of $\mathbf{1 6}$ showed a purity $>95 \%$ similar to the result of the RP-HPLC run of the unmodified peptide. These results demonstrate the compatibility of the building block with automated peptide synthesis and with the typically used protection schemes in Fmoc SPPS.

In summary, a versatile and straightforward route to oligoethylenimine-based Fmoc-polyamino acids was developed, allowing a multigram synthesis of orthogonally protected, cationic building blocks for Fmoc-SPPS. Use of these building blocks in solid-phase synthesis showed full compatibility with standard fmoc SPPS protocols and the excellent purity of the resulting poly(amidoamines). Linear and branched sequences can be synthesized, optionally fused with natural peptide sequences. The convenience of the presented strategy has recently been proven in the synthesis of a library of $>300$ defined polycationic carriers for nucleic acid delivery ${ }^{21}$ including very efficient plasmid DNA and siRNA carriers (Schaffert et al., manuscript in preparation). The novel building blocks may also find use in the synthesis of peptides with increased positive charge density. 
Scheme 2. Solid-Phase Synthesis of PAAs 11-15 Using Tryptophane-Preloaded Rink-Amide MBHA Resin Support, Followed by Deprotection and Cleavage from the Resin As Described in the Supporting Information
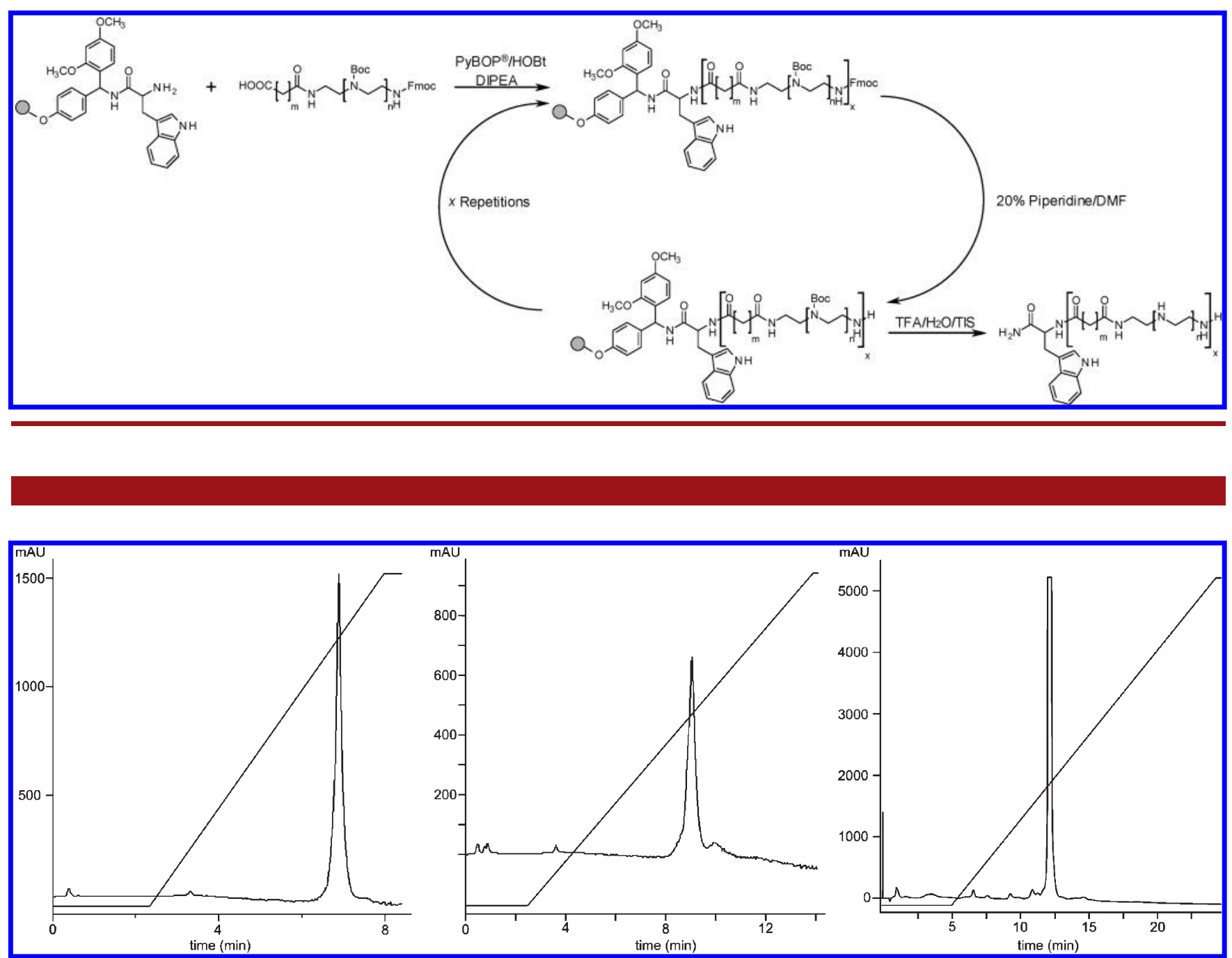

Figure 1. IEX-HPLC traces of crude (a) 11, (b) 15, and (c) $\mathbf{1 6}$ after cleavage from resin. The PAAs were eluted (2.5 $\mathrm{mL} / \mathrm{min})$ using a Resource $\mathrm{S} 1 \mathrm{~mL}$ column at rt by a linear gradient from 0 to $100 \% \mathrm{~B}(\mathrm{~A}: 20 \mathrm{mM} \mathrm{NaCl}$ in $10 \mathrm{mM} \mathrm{HCl} ; \mathrm{B}: 3 \mathrm{M} \mathrm{NaCl}$ in $10 \mathrm{mM} \mathrm{HCl})$.

Acknowledgment. We thank Olga Brück and Miriam Sindelar (LMU Munich) for skillful assistance. This work was supported by the DFG excellence cluster Nanosystems Initiative Munich (NIM), a grant by Roche Kulmbach, and the Munich Biotech Cluster $\mathrm{m}^{4} \mathrm{~T} 12$.
Supporting Information Available. Experimental synthetic procedures and characterization data (NMR spectra, MS spectra, HPLC traces). This material is available free of charge via the Internet at http://pubs. acs.org. 